wasting by tubular reabsorption of phosphate (TRP) was calculated, PU resulted increased in all.

Tumor was localized in all cases (Fig.1) and were localized in bone and soft tissue, by using functional imaging, followed by anatomical techniques. Before the introduction in routinely practice of ${ }^{68} \mathrm{Ga}$-DOTATATE-PET-CT in 2013, Octreoscan-SPECT/CT and ${ }^{18} \mathrm{~F}$ FDG-PET were used as imaging modalities. Since 2013, diagnostic delay consistently reduced, from $8.6 \pm 8.3 \mathrm{yrs}$ (7 patients) to $4.5 \pm 2.6$ yrs (9 patients), confirming higher diagnostic accuracy of ${ }^{68} \mathrm{Ga}$-DOTATATE-PET-CT.

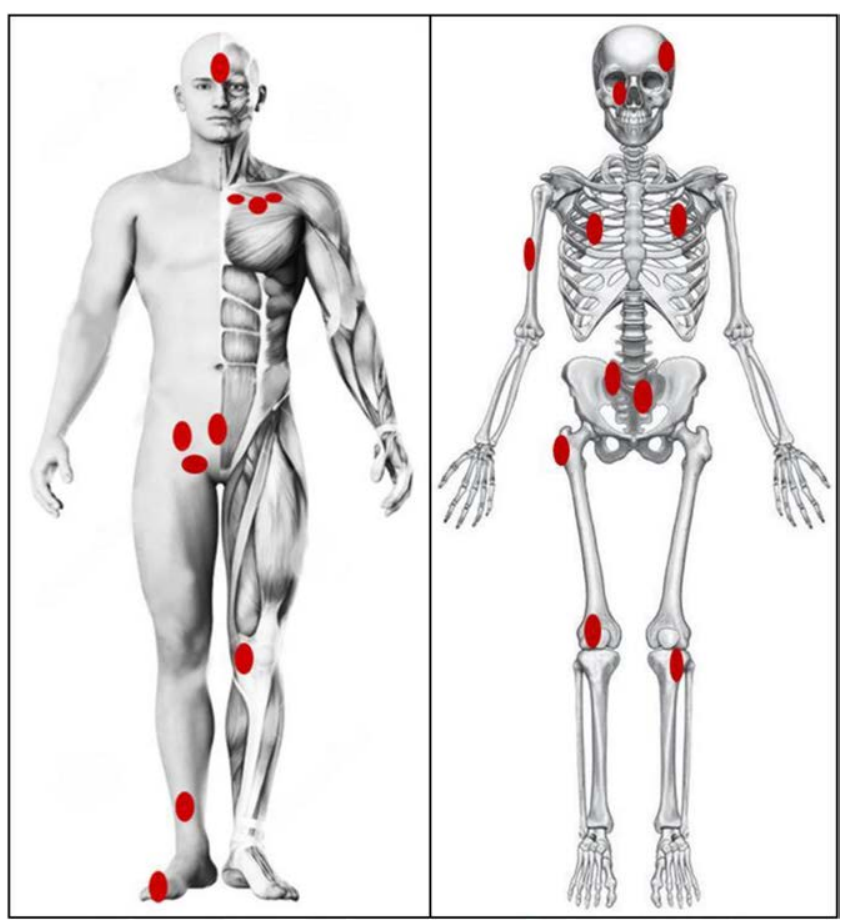

Figure 1.

13 patients underwent surgery; in two cases surgery was not possible due to tumor location, so pharmacological support with phosphate supplements and calcitriol was started; a patient underwent to TC-guided radiofrequency ablation. After surgery, 7 patients experienced a complete remission, 3 had a persistence of the disease, and 3 an overtime relapse, even after a longstanding normalization of PS (6 years). After surgical tumor removal, PS significantly increased in few days (from $1.36 \pm 0.39$ to $2.9 \pm 1.1, p=0.0001$ ), while iFGF-23 levels tended to rapidly decreased (from $396.6 \pm 707.3$ to $62.8 \pm 78.4$ ). Before the introduction of ${ }^{68} \mathrm{Ga}$-DOTATATE-PET-CT, 6 patients underwent to imaging-guided closed biopsy to confirm tumor localization; by using ${ }^{68} \mathrm{Ga}$-DOTATATE-PET-CT only 2 subjects had closed biopsy. Furthermore, in our population only patients who had biopsy to detect the lesion (7 patients) had relapses compared to patients who did not

Conclusion: To our knowledge, this is the widest European cohort of patients affected by TIO reported in the last two decades. We confirm an important delay between symptoms onset and diagnosis. To locate tumor, a stepwise approach is recommended, starting with a thorough medical history and physical examination, followed by functional imaging, preferring ${ }^{68} \mathrm{Ga}$-DOTATATE-PET-CT. Tumor biopsy is not recommended due to the potential cell spilling. Surgery is considered the only definitive treatment, aiming to a wider excision. Active surveillance is always needed, due to the possible relapses, even after a long period of complete clinical and biochemical remission.

Disclosure of Interests: : Chiara Crotti: None declared, Francesca Bartoli: None declared, Maria Manara Consultant of: Consultant and/or speaker for Eli-Lilly, MSD, Sanofi-Genzyme, Novartis, Alfa Wasserman and Cellgene, Speakers bureau: Consultant and/or speaker for Eli-Lilly, MSD, Sanofi-Genzyme, Novartis, Alfa Wasserman and Cellgene, Primo Andrea Daolio: None declared, Francesca Zucchi: None declared, Roberto Caporali Consultant of: AbbVie; Gilead Sciences, Inc.; Lilly; Merck Sharp \& Dohme; Celgene; Bristol-Myers Squibb; Pfizer; UCB, Speakers bureau: Abbvie; Bristol-Myers Squibb; Celgene; Lilly; Gilead Sciences, Inc; MSD; Pfizer; Roche; UCB, Luigi Sinigaglia: None declared, Massimo Varenna: None declared

DOI: 10.1136/annrheumdis-2020-eular.4486

\section{THU0422 \\ CALCIUM PYROPHOSPHATE CRYSTAL DEPOSITION WITHIN TOPHUS LOBULE: A FREQUENT ASSOCIATION OBSERVED IN LONG-TIME COURSE TOPHI}

H. K. Ea ${ }^{1}$, O. Olivier ${ }^{1}$, N. N. Pham ${ }^{2}$, V. Frochot ${ }^{3}$, D. Bazin ${ }^{4}$, C. Marty ${ }^{1}$, A. Ostertag ${ }^{1}$, J. D. Laredo ${ }^{5}$, P. Richette ${ }^{1}$, Q. D. Nguyen ${ }^{6}$, T. Bardin ${ }^{1} .{ }^{1}$ Universite de Paris, UMR 1132, BIOSCAR, Paris, France; ${ }^{22}$ French-Vietnamese Research Center on Gout and Chronic Diseases, Vien Gut Medical Clinic., Ho Chi Minh City, Vietnam: ${ }^{3}$ HUEP - Hôpital Tenon, Sorbonne Universite - UMR S1155, Explorations Fonctionnelles Multidisciplinaires, Paris, France; ${ }^{4}$ Institut de Chimie Physique, Université Paris-Saclay et CNRS - UMR8000, Orsay, France; ${ }^{5}$ Hôpital Lariboisière, Service de Radiologie, Paris, France; ${ }^{6}$ French-Vietnamese Research Center on Gout and Chronic diseases, Vien Gut Medical Clinic., Ho Chi Minh City, Vietnam

Background: Calcium pyrophosphate (CPP) crystals and monosodium urate (MSU) crystals are frequently found in the same synovial fluids of gouty patients suggesting an interaction in crystal formation and deposition. This association has never been reported in tophus.

Objectives: we aimed to describe the prevalence of CPP crystal deposition in tophus and to determine the associated risk factors.

Methods: 22 tophi consecutively harvested were fixed in $4 \%$ paraformaldehyde and embedded in paraffin. $5-\mu \mathrm{m}$ thick sections were analyzed by compensated polarized microscopy (CPM) after hematoxylin and eosin staining. Characterization of CPP crystals were performed by scan electronic microscopy (SEM) and Fourier transform infrared (FTIR) spectroscopy. Clinical characteristics were compared between patients having tophus with CPP deposition and patients having tophus without CPP crystals.

Results: All tophi appeared multi-lobulated depositions of MSU crystals separated by fibrous tissue and surrounded by a foreign giant cell reaction. CPP crystals were identified in few lobules of 5 tophi (22.7\%) harvested from 3 great toes, 1 elbow bursa and 1 finger of 5 patients. CPP crystals formed aggregate deposition within the lobule of MSU crystals. Both monoclinic and triclinic CPP crystal phases were identified by CPM, SEM and FTIR. Tophi were harvested from 22 male gouty patients with a mean age of $50.8(28-66)$ years and a mean BMl of $24.2 \mathrm{~kg} / \mathrm{m} 2$ (18.9-29.4). Mean serum urate level (SUL) was $499 \pm 107 \mu \mathrm{mol} / \mathrm{L}$. 59\% of patients had chronic renal disease stage 2 or $3,40.9 \%$ dyslipidemia, $22.7 \%$ type 2 diabetes mellitus, $13.6 \%$ hypertension and $50 \%$ obesity. Patients with tophi containing CPP deposition were older (61.2 [56-66] vs 47.8 [28-64] years, $\mathrm{p}=0.009$ ) and had a longer gout duration (19 [10-31] vs 9 [3-20] years, $p=0.007$ ) and tophus duration (11.4 [8-16] vs 4.5 [1-9] years, $p<0.0001$ ) than patients with tophi alone. Tophi did not display calcification on radiographies performed before surgery. However, the density of tophi containing CPP crystal deposition was higher than the density of tophi without CPP crystals (51 [25-100] vs $21.5 \%$ [0-40], $p=0.009$ ). The proportion of bone erosion and gout arthropathy was similar between the two groups. Similarly, no difference was observed for SUL $(467 \pm 43$ vs $509 \pm 109 \mu \mathrm{mol} / \mathrm{L})$, estimated glomerular filtration rate $(76.6 \pm 11.9$ vs $74.9 \pm 15.7 \mathrm{ml} / \mathrm{min} / 1.73 \mathrm{~m} 2)$ and prevalence of comorbidities. Interestingly, no calcification was detected on knee and wrist radiographies of patients with tophi containing CPP deposition.

Conclusion: These results reported for the first time, in a small sample size, that CPP crystal deposition occurred within tophus lobules. They suggested that long-time course tophi might act as a facilitating agent of CPP nucleation. This hypothesis needs specific confirmation studies

Disclosure of Interests: : None declared

DOI: 10.1136/annrheumdis-2020-eular.6057

\begin{tabular}{l|l}
\hline THU0423 & ADHERENCE TO URATE-LOWERING THERAPY IN \\
PATIENTS WITH SEVERE GOUT WHO RECEIVED \\
CANAKINUMAB FOLLOWING A 5-YEAR \\
RETROSPECTIVE ANALYSIS
\end{tabular}

M. Eliseev ${ }^{1}$, O. Sheliabina ${ }^{1} .{ }^{1}$ V.A. Nasonova Research Institute of Rheumatology, Moscow, Russian Federation

Background: The adherence to lowering therapy for gout is low, including in chronic severe gout. Whether interleukin 1 inhibitors may contribute to better adherence is unknown.

Objectives: To compare adherence to urate-lowering therapy in patients with severe gout who received canakinumab versus patients who received standard anti-inflammatory therapy (NSAIDs, glucorticoids, colchicine).

Methods: Of the 513 patients with gout observed at the V.A. Nasonova Research Institute of Rheumatology, Moscow from 2013 to 2014 y 247 patients with the most severe gout, requiring regular symptomatic treatment, were selected. Of these, 25 patients $(3(12 \%)$ women and $22(88 \%)$ men), the average age of $54.5 \pm 12.7 \mathrm{~g}$, received (at least 1) canakinumab injection of $150 \mathrm{mg}$ subcutaneously as a symptomatic therapy, the remaining 222 patients (men) mean age 